\title{
PREDICTING THE PROPERTIES OF RECOMBINANT INBRED LINES DERIVED BY SINGLE SEED DESCENT FOR TWO OR MORE CHARACTERS SIMULTANEOUSLY
}

\author{
H. S. POONI and J. L. JINKS \\ Department of Genetics, University of Birmingham, Birminghom B15 2TT
}

Received 1.vii.77

\begin{abstract}
SUMMARY
The univariate method of predicting the properties of the inbred lines produced by single seed descent for single or pairs of independent characters is extended to predict their properties for two or more characters simultaneously irrespective of their interrelationships. The bivariate and trivariate predictions for two and three characters segregating simultaneously require only one parameter, the additive genetic correlation between pairs of characters, in addition to those required for the univariate case. Satisfactory estimates of all the parameters can be obtained early in the inbreeding programme for an $F_{2}$ triple test-cross.

The procedures for making bivariate and trivariate predictions are illustrated using parameters estimated from an inbred triple test-cross and for one pair of characters from an $F_{2}$ triple test-cross, all the material being derived from a cross between varieties 1 and 5 of Nicotiana rustica. The predictions are compared with the properties of a random sample of $80 F_{11}$ families derived by single seed descent from the same cross.

Although there appears to be a good overall agreement between the predicted and observed properties of the $F_{11}$ families, a statistical test of the accuracy of the predictions must await larger sample sizes than the $\mathbf{8 0}$ families currently available.
\end{abstract}

\section{INTRODUGTION}

Jinks AND Pooni (1976) have described and illustrated procedures for predicting the properties of the inbred lines produced by single seed descent following a cross between two inbred parents both in the absence and presence of non-allelic interactions. In general there was close agreement between these predictions and the observed properties of such inbred lines even when the distribution of the inbreds was significantly non-normal (Pooni, Jinks and Cornish, 1977). Their procedures, however, will lead to useful joint predictions for two or more characters simultaneously only if these characters are independent. Simultaneous predictions for two or more characters, irrespective of the correlations among them, would be of considerable practical value as well as of theoretical interest. In this paper, therefore, we extend our univariate procedures to cover the joint segregation of two and three characters so that the proportion of inbreds expected to fall outside of some predetermined limits, such as those set by any particular combination of parental scores, can be predicted. It will be shown that this extension requires no additional experimentation and provides bivariate and trivariate predictions that are acceptable in practice. 


\section{EXPEGTED PROBABILITIES}

At the univariate level we concentrated on the allocation of the inbred lines to one of three classes, namely, those scoring higher than the higher scoring parent $\mathrm{P}_{1}$; those scoring lower than the lower scoring parent $\mathrm{P}_{2}$; and those falling between the limits set by the parental scores. We could, of course, have equally used any other limits, for example, the $F_{1}$ score or the $P_{1}$ score plus any value we care to specify without any change in the procedures. Having chosen our criteria, we predict the proportion of inbred lines falling outside of the limits by solving the relevant univariate probability integrals. For example, the expected proportion of inbred lines with a score greater than $\mathrm{P}_{1}$ is obtained from $\int_{P_{1}}^{\infty} f(x) . d x$ and the corresponding proportion for those with lower scores than $\tilde{P}_{2}$ is obtained from $\int_{-\infty}^{P_{2}} f(x) \cdot d x$ of a normal distribution with mean $\mu$ and standard deviation $\sigma$.

Similarly, it is possible to allocate the inbreds to nine classes if they are scored simultaneously for two characters, say $x_{1}$ and $x_{2}$. If, however, we retain the same criteria, four of these classes only would be of direct interest to us, namely, those which predict the proportions of inbred lines which score (1) higher than $\mathrm{P}_{1 x 1}$ * and higher than $\mathrm{P}_{1 x 2}\left(>\mathrm{P}_{1 x 1}>\mathrm{P}_{1 x 2}\right)$; (2) lower than $\mathrm{P}_{2 x 1}$ and lower than $\mathrm{P}_{2 x 2}\left(<\mathrm{P}_{2 x 1}<\mathrm{P}_{2 x 2}\right)$; (3) lower than $\mathrm{P}_{2 x 1}$ and higher than $\mathrm{P}_{1 x 2}\left(<\mathrm{P}_{2 x 1}>\mathrm{P}_{1 x 2}\right)$; and (4) higher than $\mathrm{P}_{1 x 1}$ and lower than $\mathrm{P}_{2 x 2}\left(>\mathrm{P}_{1 x 1}<\mathrm{P}_{2 x 2}\right)$. Following the univariate example these probabilities can be obtained from

$$
\begin{aligned}
& \int_{P_{1 \times 1}}^{\infty} \int_{P_{1 \times 2}}^{\infty} f\left(x_{1}, x_{2}\right) \cdot d_{x 1} \cdot d_{x 2} \text { for }(1) \\
& \int_{-\infty}^{P_{2 x 1}} \int_{-\infty}^{P_{2 x 2}} f\left(x_{1}, x_{2}\right) \cdot d_{x 1} \cdot d_{x 2} \text { for }(2) \\
& \int_{-\infty}^{P_{2} x_{1}} \int_{P_{1 x 2}}^{\infty} f\left(x_{1}, x_{2}\right) \cdot d_{x 1} \cdot d_{x 2} \text { for }(3) \text { and } \\
& \int_{P_{1 x 1}}^{\infty} \int_{-\infty}^{P_{2 x 2}} f\left(x_{1}, x_{2}\right) \cdot d_{x 1} \cdot d_{x 2} \text { for }(4),
\end{aligned}
$$

which are the bivariate integrals of a normal bivariate distribution with means $\mu_{1}$ and $\mu_{2}$, standard deviations $\sigma_{1}$ and $\sigma_{2}$ and the correlation coefficient $\rho_{12}$.

On the same criteria, for three characters $x_{1}, x_{2}$ and $x_{3}$ there are eight permutations of the parental scores that would be of particular interest and the proportion of inbred lines falling outside of the limits set by any parental combination can be obtained from the appropriate trivariate integral. For example, the proportion of inbred lines with scores consistently higher than the higher scoring parent for all the three characters $\left(>\bar{P}_{1 x 1}>\bar{P}_{1 x 2}>\bar{P}_{1 x 3}\right)$ can be obtained from $\int_{\bar{P}_{1 \times 1}}^{\infty} \int_{\bar{P}_{1 \times 2}}^{\infty} \int_{P_{1 \times 3}}^{\infty} f\left(x_{1}, x_{2}, x_{3}\right) \cdot d_{x 1} \cdot d_{x 2} \cdot d_{x 3}$, the tri-

\footnotetext{
* $\mathrm{P}_{1 x_{1}}$ represents the higher scoring of the two parents for character $x_{1}$.
} 
variate integral of a normal trivariate distribution with means $\mu_{1}, \mu_{2}$ and $\mu_{3}$, standard deviations $\sigma_{1}, \sigma_{2}$ and $\sigma_{3}$ and correlation coefficients $\rho_{12}, \rho_{13}$ and $\rho_{23}$ for $x_{1}$ and $x_{2}, x_{1}$ and $x_{3}$ and $x_{2}$ and $x_{3}$ respectively.

\section{Parameters}

Where an additive genetic and additive environmental model adequately accounts for all the variability among the inbred lines for all the characters, the $\mu$ 's and $\sigma$ 's required to define the multivariate distribution of an inbred population derived by single seed descent for the $i$ th character can be replaced by the corresponding maximum likelihood estimates of $m_{x i}$ and $\left(D_{x i}+E_{x i}\right)^{\frac{1}{2}}$. The parental scores $\bar{P}_{1 x i}$ and $\bar{P}_{2 x i}$ can also be replaced by $m_{x i}+[d]_{x i}$ and $m_{x i}-[d]_{x i}$ respectively. Furthermore, since the multivariate distribution can itself be standardised to give a standard multivariate distribution with $\mu$ 's equal to zero and $\sigma$ 's equal to one, the $\bar{P}_{1 x i}$ and $\bar{P}_{2 x i}$ can be replaced by the corresponding values of $[d]_{x i} /\left(D_{x i}+E_{x i}\right)^{\frac{1}{2}}$ and $-[d]_{x i} /\left(D_{x i}+E_{x i}\right)^{\frac{1}{2}}$. In most instances the $E_{x i}$ 's can be omitted because with pure-breeding lines we can reduce its value to negligible proportions by the use of appropriate experimental designs and levels of replication but more importantly we are in general predicting the genotypic performance and not just the phenotypic performance in a particular environment (Jinks and Pooni, 1976).

The only remaining parameters are the correlation coefficients. The genetic correlation between a pair of characters for coupling $(C)$ and repulsion $(R)$ linkages in the derived inbred population will be

$$
{ }_{-R}^{+C} \Sigma\left[\frac{\left(1-2 p_{i j}\right)}{\left(1+2 p_{i j}\right)} d_{x 1 i} \cdot d_{x 2 j}\right] /\left(\Sigma d_{x 1 i}^{2} \times \Sigma d_{x 2 j}^{2}\right)^{\frac{1}{2}}
$$

(In Jinks and Pooni (1976) the linkage coefficient was incorrectly given as twice this value). Here $p_{i j}$ is the recombination frequency between the $i$ th locus of $x_{1}$ and the $j$ th locus of $x_{2}$ at $F_{1}$ gametogenesis and $d_{x 1 i}$ and $d_{x 2 j}$ are the respective additive effects of these loci for the two characters. The recombination frequency $p_{i j}$ takes a value of 0.0 to 0.5 depending upon the strength of the linkage and is equal to zero for pleiotropy (Mather and Jinks, 1971). For the reasons discussed in the previous paragraph we will be interested primarily in the genetic rather than the phenotypic correlation. The best estimate of this correlation for making predictions early in the inbreeding programme will be provided by the variances and covariances of $\left(L_{1 i}+L_{2 i}\right)$, or of $\left(L_{1 i}+L_{2 i}+L_{3 i}\right)$ of an $\mathrm{F}_{2}$ triple test-cross (Kearsey and Jinks, 1968; Pooni and Jinks, 1976). For a pair of characters this estimate of the correlation has the expectation of

$$
{ }_{-R}^{+C} \Sigma\left[\left(1-2 p_{i j}\right) d_{x 1 i} d_{x 2 j}\right] /\left(\Sigma d_{x 1 i}^{2} \times \Sigma d_{x 2 j}^{2}\right)^{\frac{1}{2}},
$$

which while not equal to $\rho$ in the population of inbreds derived by single seed descent from the same $F_{2}$, is the best approximation at this stage in the inbreeding programme and it is obtainable without additional experimentation.

In the presence of epistasis $D_{x i},[d]_{x i}$ and $-[d]_{x i}$ for the $i$ th character must be replaced by $D_{x i}+I_{x i},[d]_{x i}+[i]_{x i}$ and $-[d]_{x i}+[i] x i$, respectively (Jinks and Pooni, 1976). The expectations of $\rho$ will, of course, become 
correspondingly more complex but in practice the biases introduced are neither large nor differ much between the predictions and the observations (see table 2 and Pooni and Jinks, 1976). All the parameters we require for making our predictions can, therefore, still be estimated from the six basic generations $\left(P_{1}, P_{2}, F_{1}, F_{2}, B_{1}\right.$ and $\left.B_{2}\right)$, and an $F_{2}$ triple test-cross.

\section{EXPERIMENTS AND RESULTS}

The experimental material consists of 80 pure-breeding $F_{11}$ families produced by single seed descent from a random sample of $F_{2}$ individuals of a cross between varieties $\mathrm{V}_{1}$ and $\mathrm{V}_{5}$ of Nicotiana rustica; a triple test-cross set of families obtained by crossing each of the 80 inbreds to either parent $\left(V_{1}\right.$ and $\left.V_{5}\right)$ and their $F_{1}\left(V_{1} \times V_{5}\right)$ and the six basic generations $\left(P_{1}, P_{2}\right.$, $F_{1}, F_{2}, B_{1}$ and $B_{2}$ ) derived by selfing and backcrossing $V_{1}, V_{5}$ and their $F_{1}$ amongst themselves. The material was raised in a single experiment during the summer of 1973 and individual plants were scored for three developmental heights $\left(\mathrm{H}_{1}, \mathrm{H}_{2}\right.$ and $\left.\mathrm{H}_{3}\right)$, flowering time (FT), height at flowering (HFT), leaf length and leaf width of the largest leaf blade (LL and LW), leaf spread across the plant involving largest leaf (LS) and final height $(\mathrm{FH})$. All the characters were scored in centimetres (to the nearest $0.5 \mathrm{~cm}$ ) except for FT which was scored in days. Fuller details of the experiment have already been published (Pooni and Jinks, 1976) and the estimates of $D_{x i},[d]_{x i}$ and $[i]_{x i}$ for each character are tabulated explicitly in table 4 by Pooni, Jinks and Cornish (1977) and will not be reproduced here. In table 1, however, is a summary of these results in the form of abscissa values which correspond to the $\mathrm{P}_{1}$ and $\mathrm{P}_{2}$ means (allowing for epistasis) and the corresponding predicted proportions of inbreds falling outside the limits set by these parental means.

TABLE 1

Abscissa values and the respective univariate proportions for each of the nine characters under study

\begin{tabular}{|c|c|c|c|c|}
\hline \multirow[b]{2}{*}{ Character } & \multicolumn{2}{|c|}{ Abscissa values* } & \multicolumn{2}{|c|}{ Predicted proportions } \\
\hline & $\frac{[[d]+[i]]}{\sqrt{D}}$ & $\frac{[-[d]+[i]]}{\sqrt{D}}$ & $>\bar{P}_{1}$ & $<\bar{P}_{2}$ \\
\hline $\mathrm{H}_{1}$ & $1 \cdot 50$ & $0 \cdot 04$ & 0.07 & 0.52 \\
\hline $\mathrm{H}_{2}$ & 1.76 & $0 \cdot 12$ & 0.04 & 0.54 \\
\hline $\mathrm{H}_{3}$ & 1.25 & 0.48 & $0 \cdot 11$ & 0.68 \\
\hline FT & -0.27 & -1.32 & 0.61 & $0 \cdot 10$ \\
\hline HFT & 0.37 & -0.87 & $0 \cdot 36$ & $0 \cdot 19$ \\
\hline $\mathrm{LL}$ & -0.31 & -0.65 & 0.63 & $0 \cdot 26$ \\
\hline LW & $0 \cdot 48$ & -0.60 & $0 \cdot 32$ & $0 \cdot 27$ \\
\hline $\mathrm{LS}$ & -0.58 & -0.86 & 0.72 & $0 \cdot 19$ \\
\hline $\mathrm{FH}$ & 0.44 & -1.33 & $0 \cdot 33$ & 0.09 \\
\hline
\end{tabular}

* In the presence of epistasis the estimate of $D$ will contain an epistatic component.

To predict the bivariate and multivariate properties of the inbreds derived by single seed descent we also require estimates of the genetic correlations. Although it does not yield exactly the form of the correlation required for making these predictions the best estimate in the early stages of an inbreeding programme are obtained from an $\mathrm{F}_{2}$ triple test-cross using 
the $\left(L_{1 i}+L_{2 i}\right)$ or $\left(L_{1 i}+L_{2 i}+L_{3 i}\right)$ values (section 3$)$. These are available for two of our characters only, flowering time (FT) and final height (FH) (Perkins and Jinks, 1970). For the others, therefore, we shall obtain the correlations from these expressions in the inbred triple test-cross reported in this paper (Section 4). Since this test-cross is based on a random sample of $F_{10}$ inbreds the results can be used to illustrate the procedures but not, of course, to test our ability to predict the outcome of an inbreeding programme at an early stage. The actual correlations observed between the pairs of characters in the $80 \mathrm{~F}_{11}$ 's produced by single seed descent and the estimates of these correlations from the inbred triple test-cross and the single estimate for $\mathrm{FT}$ and $\mathrm{FH}$ from the $\mathrm{F}_{2}$ triple test-cross are listed in table 2 .

TABLE 2

The correlation coefficients for the 36 pairs of characters $(1)$ observed among the $F_{11}$ inbreds in 1973 and predicted from (2) the $\left(\mathrm{L}_{11}+\overline{\mathrm{L}}_{21}+\mathrm{L}_{31}\right)$ and (3) the $\left(\hat{\mathrm{L}}_{11}+\overline{\mathrm{L}}_{2 \mathrm{i}}\right)$ components of an inbred triple test-cross

Characters

\begin{tabular}{|c|c|c|c|c|c|c|c|c|c|}
\hline \multicolumn{2}{|l|}{ Characters } & $\mathbf{H}_{2}$ & $\mathbf{H}_{3}$ & FT & HFT & LL & LW & LS & FH \\
\hline $\mathbf{H}_{1}$ & $\begin{array}{l}1 \\
2 \\
3\end{array}$ & $\begin{array}{l}0.96 \\
0.94 \\
0.94\end{array}$ & $\begin{array}{l}0.86 \\
0.84 \\
0 \cdot 84\end{array}$ & $\begin{array}{l}-0.63 \\
-0.67 \\
-0.69\end{array}$ & $\begin{array}{l}-0.10 \\
-0.33 \\
-0.38\end{array}$ & $\begin{array}{l}-0.33 \\
-0.33 \\
-0.33\end{array}$ & $\begin{array}{l}-0.35 \\
-0.42 \\
-0.38\end{array}$ & $\begin{array}{l}-0.33 \\
-0.39 \\
-0.38\end{array}$ & $\begin{array}{l}-0.17 \\
-0.33 \\
-0.37\end{array}$ \\
\hline $\mathrm{H}_{2}$ & $\begin{array}{l}1 \\
2 \\
3\end{array}$ & & $\begin{array}{l}0.94 \\
0.95 \\
0.95\end{array}$ & $\begin{array}{l}-0.74 \\
-0.80 \\
-0.81\end{array}$ & $\begin{array}{l}-0.22 \\
-0.44 \\
-0.47\end{array}$ & $\begin{array}{l}-0.38 \\
-0.44 \\
-0.43\end{array}$ & $\begin{array}{l}-0.36 \\
-0.46 \\
-0.42\end{array}$ & $\begin{array}{l}-0.40 \\
-0.52 \\
-0.49\end{array}$ & $\begin{array}{l}-0.26 \\
-0.46 \\
-0.47\end{array}$ \\
\hline $\mathrm{H}_{3}$ & $\begin{array}{l}1 \\
2 \\
3\end{array}$ & & & $\begin{array}{l}-0.86 \\
-0.89 \\
-0.89\end{array}$ & $\begin{array}{l}-0.35 \\
-0.52 \\
-0.55\end{array}$ & $\begin{array}{l}-0.38 \\
-0.47 \\
-0.46\end{array}$ & $\begin{array}{l}-0.34 \\
-0.44 \\
-0.41\end{array}$ & $\begin{array}{l}-0.41 \\
-0.54 \\
-0.52\end{array}$ & $\begin{array}{l}-0.32 \\
-0.53 \\
-0.53\end{array}$ \\
\hline FT & $\begin{array}{l}1 \\
2 \\
3\end{array}$ & & & & $\begin{array}{l}0.72 \\
0.84 \\
0.85\end{array}$ & $\begin{array}{l}0.46 \\
0.51 \\
0.53\end{array}$ & $\begin{array}{l}0.43 \\
0.41 \\
0.43\end{array}$ & $\begin{array}{l}0.51 \\
0.60 \\
0.61\end{array}$ & $\begin{array}{r}0.58 \\
0.75 \\
0.76 \\
(0.42)\end{array}$ \\
\hline HFT & $\begin{array}{l}1 \\
2 \\
3\end{array}$ & & & & & $\begin{array}{l}0.48 \\
0.44 \\
0.50\end{array}$ & $\begin{array}{l}0.45 \\
0.31 \\
0.38\end{array}$ & $\begin{array}{l}0.55 \\
0.54 \\
0.59\end{array}$ & $\begin{array}{l}0 \cdot 82 \\
0 \cdot 84 \\
0 \cdot 84\end{array}$ \\
\hline LL & $\begin{array}{l}1 \\
2 \\
3\end{array}$ & & & & & & $\begin{array}{l}0.81 \\
0.72 \\
0.77\end{array}$ & $\begin{array}{l}0.97 \\
0.95 \\
0.95\end{array}$ & $\begin{array}{l}0.74 \\
0.66 \\
0.66\end{array}$ \\
\hline LW & $\begin{array}{l}1 \\
2 \\
3\end{array}$ & & & & & & & $\begin{array}{l}0.81 \\
0.71 \\
0.76\end{array}$ & $\begin{array}{l}0.67 \\
0.53 \\
0.57\end{array}$ \\
\hline LS & $\begin{array}{l}1 \\
2 \\
3\end{array}$ & & & & & & & & $\begin{array}{l}0.79 \\
0.73 \\
0.73\end{array}$ \\
\hline
\end{tabular}
1965.

* The bracketed estimate for FT.FH is obtained from an $F_{2}$ triple test-cross conducted in

\section{(i) Estimating bivariate proportions}

The expected value of various bivariate integrals described in Section 2 can be computed for different pairs of characters by utilising the respective 
abscissa values and the bivariate density functions. However, normal bivariate probabilities have already been tabulated by various research workers and we will base our estimates on the tables produced by Owen (1956). The fundamental formula for finding any specified proportion of a bivariate distribution is given by Owen as:

$$
B(h, k, \rho)=\frac{1}{2} G(h)+\frac{1}{2} G(k)-T\left(h, a_{h}\right)-T\left(k, a_{k}\right)-\left\{\begin{array}{l}
0 \\
\frac{1}{2}
\end{array},\right.
$$

where $B(h, k, \rho)$ is the probability integral from $-\infty$ to $h$ along $X$-axis and from $-\infty$ to $k$ along $Y$-axis when the two characters are related to one another with $\rho$. $G(h)$ and $G(k)$ are the univariate integrals as obtained by Jinks and Pooni (1976) for univariate distributions and $T\left(h, a_{h}\right)$ and $T\left(k, a_{k}\right)$ are the values tabulated by Owen (loc. cit.) where $h$ and $k$ are the abscissa values for characters $x_{1}$ and $x_{2}$, respectively. Quantity $a_{h}=\frac{k-\rho h}{h\left(1-\rho^{2}\right)^{\frac{1}{2}}}$ and $a_{k}=\frac{h-\rho k}{k\left(1-\rho^{2}\right)^{\frac{1}{2}}}$ while the upper choice of zero is made if $h k>0$ or if $h k=0$ but $h+k \geqq 0$. The lower choice is automatically made for any other situation.

The $\mathcal{T}$-function is tabulated only for limited values of $a\left(a_{h}\right.$ or $\left.a_{k}\right)$ and its value for any other value of $a$ can be worked out as:

$$
\mathcal{T}(h, a)=\frac{1}{2} G(h)+\frac{1}{2} G(a h)-G(h) G(a h)-T(a h, 1 / a) .
$$

Also $T(-h, a)=T(h, a)$ and $T(h,-a)=T(-h,-a)=-\mathcal{T}(h, a)$.

We can obtain the bivariate probabilities using these formulae for each of the 36 pairs of characters which are possible from nine metrical traits. For illustrative purposes, however, we will take only $\mathrm{H}_{1}, \mathrm{H}_{3}, \mathrm{FT}, \mathrm{LL}$ and $\mathrm{FH}$ because not only do they display among themselves both positive and negative and strong and loose correlations but they also exhibit maximum variability among the nine characters for their heritabilities (see table 2 of Pooni et al., 1977). They also present a contrasting picture in respect of their levels of additive $\times$ additive epistasis [i], skewness $\left(g_{1}\right)$ and kurtosis $\left(g_{2}\right)$.

The expected probabilities for every pair of characters in respect of $\mathbf{H}_{1}$, $\mathrm{H}_{3}, \mathrm{FT}, \mathrm{LL}$ and $\mathrm{FH}$, which were worked out using the estimates of $\rho$ based on the $\left(L_{1 i}+L_{2 i}+L_{3 i}\right)$ comparison and the $F_{2}$ triple test-cross (table 2) are presented in table 3 together with the corresponding observed proportions within the sample of 80 inbreds. We will illustrate how these predicted values were obtained with particular reference to $\mathrm{H}_{1}$ and $\mathrm{H}_{3}$.

\section{(ii) Example}

The four bivariate integrals of particular interest for $\mathrm{H}_{1}$ and $\mathrm{H}_{3}$ are:

$$
\begin{aligned}
& \int_{-\infty}^{0.04} \int_{-\infty}^{0.48} f\left(x_{1}, x_{2} ; \rho_{12}\right) \cdot d_{x 1} \cdot d_{x 2} ; \\
& \int_{1.50}^{\infty} \int_{1.25}^{\infty} f\left(x_{1}, x_{2} ; \rho_{12}\right) \cdot d_{x 1} \cdot d_{x 2} ; \\
& \int_{-\infty}^{0.04} \int_{1.25}^{\infty} f\left(x_{1}, x_{2} ; \rho_{12}\right) \cdot d_{x 1} \cdot d_{x 2} \text { and }
\end{aligned}
$$


TABIE 3

The observed and predicted proportions of inbred lines which fall outside the parental range for individual characters and also lie outside the limits set by one of the four possible parental combinations for a pair of characters

Observed and Predicted Proportions

\begin{tabular}{|c|c|c|c|c|c|c|c|c|c|}
\hline \multicolumn{2}{|c|}{$\begin{array}{c}\text { Pairs of } \\
\text { characters }\end{array}$} & \multicolumn{2}{|c|}{$>P_{1 x 1} \&>P_{1 x 2}$} & \multicolumn{2}{|c|}{$<\mathbf{P}_{2 x 1} \underbrace{\&}<\mathbf{P}_{8 x 2}$} & \multicolumn{2}{|c|}{$>P_{1 x 1} \&<P_{2 x 2}$} & \multicolumn{2}{|c|}{$<\mathrm{P}_{2 x 1} \&>\mathrm{P}_{1 x 2}$} \\
\hline$x_{1}$ & $x_{2}$ & Observed & Predicted & Observed & Predicted & Observed & Predicted & Observed & Predictec \\
\hline $\mathrm{H}_{1}$ & $\mathrm{H}_{3}$ & 0.075 & 0.051 & 0.488 & 0.492 & 0.000 & 0.003 & $0 \cdot 000$ & 0.001 \\
\hline $\mathrm{H}_{1}$ & FT & 0.000 & 0.008 & $0 \cdot 000$ & 0.009 & 0.050 & 0.051 & 0.413 & 0.431 \\
\hline $\mathrm{H}_{1}$ & $\mathrm{LL}$ & $0 \cdot 013$ & 0.027 & 0.088 & 0.087 & 0.075 & 0.035 & 0.375 & 0.388 \\
\hline $\mathrm{H}_{1}$ & FH & 0.013 & $0 \cdot 010$ & 0.050 & 0.024 & 0.038 & 0.015 & 0.213 & 0.220 \\
\hline $\mathrm{H}_{3}$ & FT & 0.000 & 0.001 & 0.000 & 0.003 & 0.063 & 0.073 & 0.575 & 0.569 \\
\hline $\mathrm{H}_{3}$ & LL & 0.063 & 0.034 & $0 \cdot 138$ & 0.115 & 0.113 & 0.062 & 0.500 & 0.528 \\
\hline $\mathrm{H}_{3}$ & $\mathrm{FH}$ & 0.025 & 0.007 & 0.075 & 0.025 & 0.050 & 0.035 & 0.338 & $0 \cdot 291$ \\
\hline FT & LL & 0.475 & 0.462 & $0 \cdot 050$ & 0.062 & 0.063 & $0 \cdot 089$ & 0.013 & 0.028 \\
\hline $\mathrm{FT}$ & $\mathrm{FH}$ & 0.338 & $\begin{array}{l}0.305 \\
(0.310) \dagger\end{array}$ & 0.038 & $\begin{array}{c}0 \cdot 049 \\
(0 \cdot 027)\end{array}$ & 0.013 & $\begin{array}{c}0.006 \\
(0.026)\end{array}$ & 0.000 & $\begin{array}{c}0.002 \\
(0.012)\end{array}$ \\
\hline LL & FH & 0.363 & 0.298 & $0 \cdot 113$ & 0.068 & 0.013 & 0.012 & 0.025 & 0.017 \\
\hline
\end{tabular}

$\dagger$ The bracketed values were obtained by using the $F_{2}$ triple test-cross correlation (see table 2).

$$
\int_{1 \cdot 50}^{\infty} \int_{-\infty}^{0.48} f\left(x_{1}, x_{2} ; \rho_{12}\right) \cdot d_{x 1} \cdot d_{x 2}
$$

which correspond with the proportions of inbreds having their scores $<\mathrm{P}_{2 x 1}<\mathrm{P}_{2 x 2},>\mathrm{P}_{1 x 1}>\mathrm{P}_{1 x 2},<\mathrm{P}_{2 x 1}>\mathrm{P}_{1 x 2}$ and $>\mathrm{P}_{1 x 1}<\mathrm{P}_{2 x 2}$ respectively (see Section 2). Graphically, these proportions are given by the volumetric integrations over the four areas in fig. 1.

The first integral $\left(<\mathrm{P}_{2 x 1}<\mathrm{P}_{2 x 2}\right)$ is simply solved as $B(0.04,0.48 ; 0.84)$ the value of which is equal to:

$$
\begin{gathered}
\frac{1}{2}(0.52)+\frac{1}{2}(0.68)-T(0.04,20.67)-T(0.48,-1.40)-0 \\
=0.26+0.34-0.2386+0.1306=0.492
\end{gathered}
$$

The second integral

$$
\int_{1.50}^{\infty} \int_{1.25}^{\infty} f\left(x_{1}, x_{2} ; 0 \cdot 84\right) . d x_{1} . d x_{2},
$$

however, is symmetrical with

$$
\int_{-\infty}^{-1.50} \int_{-\infty}^{-1.25} f\left(x_{1}, x_{2} ; 0 \cdot 84\right) \cdot d x_{1} \cdot d x_{2}
$$

which equals $B(-1.50,-1.25 ; 0.84)$ and is solved as

$$
\frac{1}{2}(0 \cdot 07)+\frac{1}{2}(0 \cdot 11)-T(-1 \cdot 50,-1 \cdot 01)-T(-1 \cdot 25,0.67)-0=0.0506 .
$$

Similarly

$$
\begin{aligned}
& \int_{-\infty}^{0.04} \int_{1.25}^{\infty} f\left(x_{1}, x_{2} ; 0.84\right) . d x_{1} \cdot d x_{2}=\int_{-\infty}^{0.04} \int_{-\infty}^{-1.25} f\left(x_{1}, x_{2} ;-0.84\right) . d x_{1} . d x_{2} \\
& \quad=B(0.04,-1.25 ;-0.84)=\frac{1}{2}(0.52)+\frac{1}{2}(0.11)-T(0.04,-59.43) \\
& \quad=0.26+0.055+0.2397-0.0533-0.50=0.0014 . \quad-T(-1.25,1.50)-\frac{1}{2} \\
& 40,3-B
\end{aligned}
$$




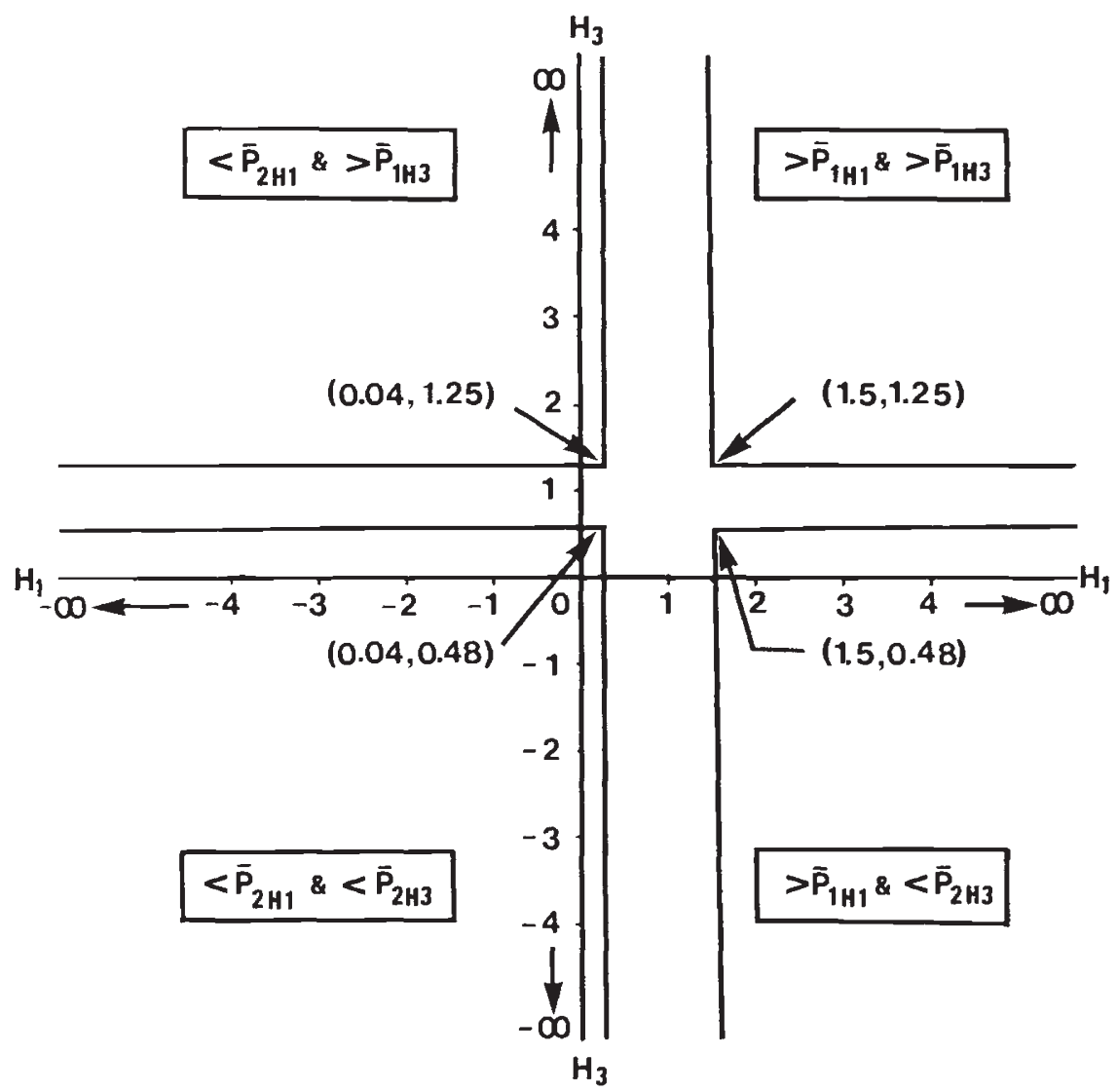

Fig. 1. - The area covered by each of the four bivariate integrals which represent proportions of inbreds falling outside various combinations of parental scores for $\mathrm{H}_{1}$ and $\mathrm{H}_{3}$.

Lastly, the fourth integral

$\int_{1.50}^{\infty} \int_{-\infty}^{0.48} f\left(x_{1}, x_{2} ; 0.84\right) . d x_{1} . d x_{2}=\int_{-\infty}^{-1.50} \int_{-\infty}^{0.48} f\left(x_{1}, x_{2} ;-0.84\right) . d x_{1} . d x_{2}$,

whose value is given by $B(-1 \cdot 50,0.48 ;-0.84)$ which in turn equals

$$
\frac{1}{2}(0.07)+\frac{1}{2}(0.68)-T(-1.50,0.96)-T(0.48,-4.23)-\frac{1}{2} \text {. }
$$

By substitution this becomes $0.035+0.34-0.0308+0.1589-0.50=0.0031$.

These expected probabilities are, as usual, based on the assumption that the observations are taken from an inbred population of infinite size. The observed and expected proportions therefore can deviate from each other simply because the observed probabilities are obtained from a small sample of such a population. These deviations, however, should be marginal and non-significant if our assumptions about the normality of a bivariate population hold good and if the sample truly represents the population in question. One would normally, therefore, test the deviations between the observed and expected proportions (table 3 ) as a $\chi^{2}$ but because of the very low expectations of some of the classes for a sample size of 80 this test has not been 
applied and its application must await large sample sizes. It is clear, however, that the expectations are the correct order of magnitude. And in one case only $\left(\mathrm{H}_{3}, \mathrm{FH}\right)$ which involves the character $\mathrm{H}_{3}$ that showed significant deviations in the univariate predications (Pooni et al., 1977) are the deviations between observed and expected large enough to cause concern.

\section{(iii) Estimating trivariate proportions}

The bivariate technique can be readily extended to predict the properties of inbreds in respect of three characters, $x_{1}, x_{2}$ and $x_{3}$. For example, the probability of inbreds having higher scores than the $P_{1}$ 's in respect of all the three characters can be obtained from a trivariate integral

$$
\int_{\bar{P}_{1 \times 1}}^{\infty} \int_{\bar{P}_{1 \times 2}}^{\infty} \int_{\bar{P}_{1 \times 3}}^{\infty} f\left(x_{1}, x_{2}, x_{3} ; \rho_{12}, \rho_{13}, \rho_{23}\right) \cdot d x_{1} \cdot d x_{2} \cdot d x_{3}
$$

and there are seven other similar integrals each representing a permutation of parental scores. Their numerical values can be obtained by various methods, the simplest being to use the standardised normal trivariate tables provided by Steck (1958). This method utilises the abscissa values and the correlation coefficients already derived for bivariate distribution.

The fundamental formula used for obtaining trivariate integrals is:

$$
\begin{aligned}
C(h, & \left.k, m ; \rho_{12}, \rho_{13}, \rho_{23}\right)=\frac{1}{2}\left[\left(1-\delta_{a_{i} c_{i}}\right) G(h)+\left(1-\delta_{a 2 c 2}\right) G(k)\right. \\
& \left.+\left(1-\delta_{a 3 c 3}\right) G(m)\right]-\frac{1}{2}\left[T\left(h, a_{1}\right)+T\left(h, c_{1}\right)+T\left(k, a_{2}\right)+T\left(k, c_{2}\right)\right. \\
& \left.+T\left(m, a_{3}\right)+T\left(m, c_{3}\right)\right]-\left[S\left(h, a_{1}, b_{1}\right)+S\left(h, c_{1}, d_{1}\right)+S\left(k, a_{2}, b_{2}\right)\right. \\
& \left.+S\left(k, c_{2}, d_{2}\right)+S\left(m, a_{3}, b_{3}\right)+S\left(m, c_{3}, d_{3}\right)\right] .
\end{aligned}
$$

Here, all the $G$-functions and $T$-functions are the same as those for the bivariate distribution and $h, k$ and $m$ are the abscissa values for $x_{1}, x_{2}$ and $x_{3}$ respectively. The values of all the $a$ 's, $b$ 's, $c$ 's and $d$ 's are the functions of their respective abscissa values and the correlation coefficients while $\delta$ 's are either zero or one, depending upon the product of the signs of their subscripts.

The values of $S$-functions and further details of these formulae have been given by Steck (1958). The $S$-tables however are based on the assumption that all the three abscissa values are either negative or positive in sign. Any combination of negative and positive values must therefore be adjusted accordingly to make them compatible with these formulae (see example below).

\section{(iv) Example}

Trivariate predictions can be made for any of the 84 combinations of three out of nine characters under study. However, the combination involving $\mathrm{H}_{1}$, LL and $\mathrm{FH}$ has been selected as an illustrative example because these characters not only incorporate a wide range of negative and positive correlations and different levels of heritability and epistasis but they also represent the three principal components which jointly are responsible 
for most of the morphological variability in the $V_{1} \times V_{5}$ cross of Nicotiana rustica (Eaves and Brumpton, 1972; Perkins, 1972). The probability of any inbred attaining a score $>P_{1 H 1}>P_{1 L L}>P_{1 F H}$ can therefore be obtained from the corresponding trivariate integrand:

$$
\int_{1.50}^{\infty} \int_{-0.31}^{\infty} \int_{0.44}^{\infty} f\left(x_{1}, x_{2}, x_{3} ;-0.33,-0.33,0.66\right) \cdot d x_{1} . d x_{2} . d x_{3}
$$

If the normality of the trivariate distribution is assumed, the same integrand is symmetrical and can therefore be replaced by

$$
\int_{-\infty}^{-1.50} \int_{-\infty}^{+0.31} \int_{-\infty}^{-0.44} f\left(x_{1}, x_{2}, x_{3} ;-0.33,-0.33,0.66\right) . d x_{1} . d x_{2} . d x_{3}
$$

\section{TABLE 4}

The observed and expected numbers of inbreds out of 80 for the bivariate classes derived from the five metrical traits $\left(\mathrm{H}_{1}, \mathrm{H}_{3}, \mathrm{FT}, \mathrm{LL}\right.$ and $\left.\mathrm{FH}\right)$ selected for the present study

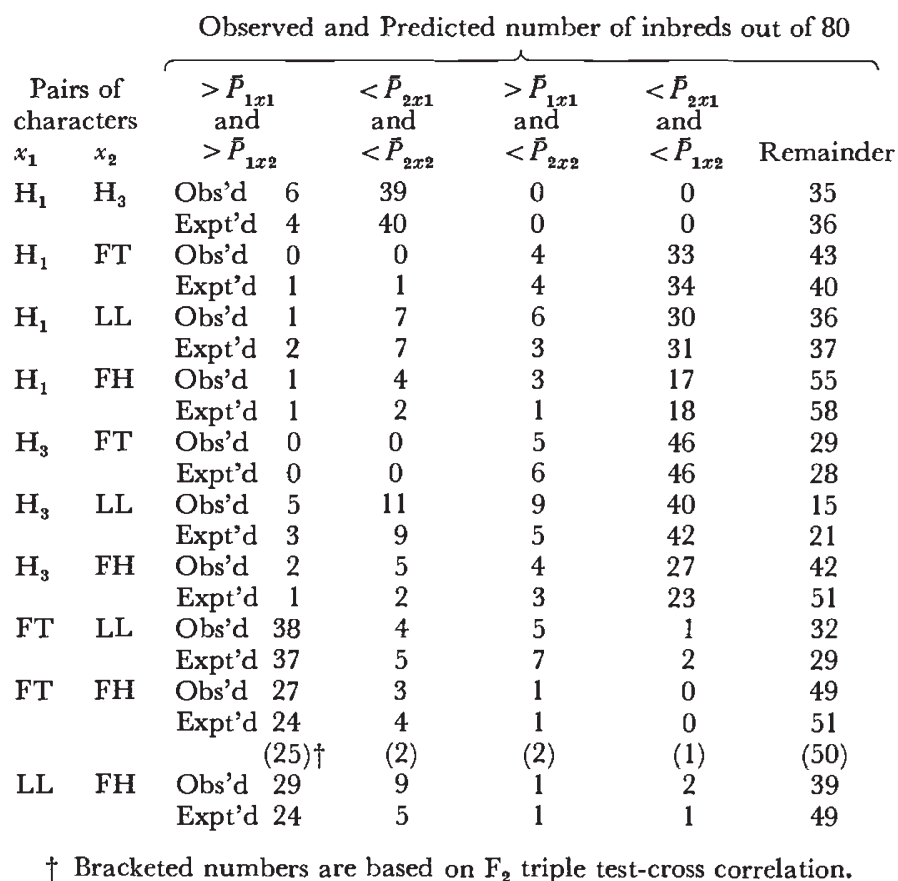

The abscissa values $-1.50,0.31$ and -0.44 however, do not satisfy the conditions that they should have the same sign. This problem is solved by a simple mathematical manipulation whereby any trivariate integral is replaced by a similar integrand which has abscissa values with the required signs. The latter can then be solved.

Integrand (2) can be rewritten as:

$$
\int_{-\infty}^{-1.50} \int_{-0.31}^{\infty} \int_{-\infty}^{-0.44} f\left(x_{1}, x_{2}, x_{3} ; 0.33,-0.33,-0.66\right) . d x_{1} . d x_{2} . d x_{3}
$$


which is equal to

$\int_{-\infty}^{-1.50}\left(\int_{-\infty}^{\infty}-\int_{-\infty}^{-0.31}\right) \int_{-\infty}^{-0.44} f\left(x_{1}, x_{2}, x_{3} ; 0.33,-0.33,-0.66\right) d x_{1} . d x_{2} . d x_{3}$

Now integrand (4) consists of two distinct parts. The first of which,

$$
\int_{-\infty}^{-1.50} \int_{-\infty}^{\infty} \int_{-\infty}^{-0.44} f\left(x_{1}, x_{2}, x_{3} ; 0.33,-0.33,-0.66\right) d x_{1} . d x_{2} . d x_{3} \text {, }
$$

is essentially a bivariate integral

$$
\int_{-\infty}^{-1.50} \int_{-\infty}^{-0.44} f\left(x_{1}, x_{2} ;-0.33\right) \cdot d x_{1} \cdot d x_{3}
$$

whose value can be obtained from $B(-1.50,-0.44 ;-0.33)$. The other part

$$
\int_{-\infty}^{-1.50} \int_{-\infty}^{-0.31} \int_{-\infty}^{-0.44} f\left(x_{1}, x_{2}, x_{3} ; 0.33,-0.33,-0.66\right) d x_{1} \cdot d x_{2} \cdot d x_{3}
$$

is a trivariate integrand which now satisfies the condition that all the abscissa values have the same sign. Its solution therefore, can be obtained as $-C(-1.50,-0.31,-0.44 ; 0.33,-0.33,-0.66)$.

The bivariate integral $B(-1.50,-0.44 ;-0.33)$ has already been obtained (table 3 ) and its value is 0.00995 . The trivariate integrand $C(-1.50,-0.31,-0.44 ; 0.33,-0.33,-0.66)$ is equal to

$$
\begin{aligned}
& \frac{1}{2}(1-1) G(-1 \cdot 50)+(1-0) G(-0 \cdot 31)+(1-0) G(-0 \cdot 44)-\frac{1}{2}[T(-1 \cdot 50,0 \cdot 66) \\
& \quad+T(-1 \cdot 50,-0 \cdot 13)+T(-0 \cdot 31,4 \cdot 78)+T(-0 \cdot 31,2 \cdot 77)+T(-0 \cdot 44,1 \cdot 82) \\
& \quad+T(-0 \cdot 44,3 \cdot 96)]-[S(-1 \cdot 50,0 \cdot 66,0 \cdot 54)+S(-1 \cdot 50,-0 \cdot 13,-5 \cdot 64) \\
& \quad+S(-0 \cdot 31,4 \cdot 78,0 \cdot 75)+S(-0 \cdot 31,2 \cdot 77,1 \cdot 91)+S(-0 \cdot 44,-0 \cdot 13,-5 \cdot 64) \\
& \quad+S(-0.44,1 \cdot 82,2 \cdot 05)],
\end{aligned}
$$

which takes its values from

$$
\begin{array}{r}
\frac{1}{2}(0 \cdot 0+0 \cdot 37+0 \cdot 33)-\frac{1}{2}(0 \cdot 02625-0.00664+0 \cdot 1638+0 \cdot 1870+0 \cdot 1760+0 \cdot 1429) \\
-[0.0023-0 \cdot 0114+0.0096+0 \cdot 0002+0 \cdot 0002+0.0045] \text { as } 0 \cdot 0002
\end{array}
$$

The proportion of inbreds scoring $>\bar{P}_{1 H 1}>\bar{P}_{1 L L}>\bar{P}_{1 F H}$ is therefore given by $B(-1.50,-0.44 ;-0.33)-C(-1.50,-0.31,-0.44 ; 0.33,-0.33$, $-0.66)=0.00995-0.0002=0.00975$.

Predicted proportions of inbreds with scores falling outside the limits set by the parental scores have been obtained for the remaining seven parental combinations and are tabulated along with the observed proportions in table 5. The predicted and observed numbers out of 80 are also given. Again the sample size of 80 is too small to permit a reliable statistical test of the agreement between the observed and expected frequencies and such a test must await larger sample sizes. However, the predictions are clearly the right relative orders of magnitude. 
TABLE 5

The observed and predicted trivariate proportions and the corresponding numbers of inbreds rounded off as whole numbers for the trivariate distribution of $\mathrm{H}_{3}, \mathrm{LL}$ and $\mathrm{FH}$

\begin{tabular}{|c|c|c|c|c|c|c|}
\hline \multicolumn{3}{|c|}{$\begin{array}{l}\text { Parental combinations for } \\
\text { various characters }\end{array}$} & \multicolumn{2}{|c|}{$\begin{array}{l}\text { Observed and predicted } \\
\text { proportions }\end{array}$} & \multicolumn{2}{|c|}{$\begin{array}{l}\text { Observed and predicted } \\
\text { numbers of inbreds } \\
\text { (out of } 80 \text { ) }\end{array}$} \\
\hline $\mathrm{H}_{1}$ & LL & FH & Observed & Predicted & Observed & Predicted \\
\hline $\begin{array}{l}>P_{1} \\
>P_{1} \\
>P_{1} \\
>P_{1} \\
<P_{2} \\
<P_{2} \\
<P_{2} \\
<P_{2}\end{array}$ & $\begin{array}{c}>P_{1} \\
>P_{1} \\
<P_{2} \\
<P_{2} \\
>P_{1} \\
>P_{1} \\
<P_{2} \\
<P_{2} \\
\text { Remainder }\end{array}$ & $\begin{array}{l}>P_{1} \\
<\bar{P}_{2} \\
>P_{1} \\
<P_{2} \\
>P_{1} \\
<P_{2} \\
>P_{1} \\
<P_{2}\end{array}$ & $\begin{array}{l}0.0125 \\
0.0000 \\
0.0000 \\
0.0375 \\
0 \cdot 2000 \\
0.0125 \\
0.0125 \\
0 \cdot 0375 \\
0.6875\end{array}$ & $\begin{array}{l}0 \cdot 0099 \\
0 \cdot 0034 \\
0 \cdot 0018 \\
0 \cdot 0621 \\
0 \cdot 3279 \\
0 \cdot 0409 \\
0 \cdot 0172 \\
0 \cdot 0501 \\
0 \cdot 4827\end{array}$ & $\begin{array}{r}1 \\
0 \\
0 \\
3 \\
16 \\
1 \\
1 \\
1 \\
3 \\
55\end{array}$ & $\begin{array}{r}1 \\
0 \\
0 \\
5 \\
26 \\
3 \\
3 \\
1 \\
4 \\
40\end{array}$ \\
\hline
\end{tabular}

\section{Discussion ANd Gonglusion}

We have now extended our univariate method for predicting the properties of a random set of inbreds in respect of individual characters to predict their properties in respect of two or three characters simultaneously, irrespective of whether they are independent or not. In theory we can make these predictions by adding one new parameter, the additive genetic correlation between pairs of characters, to the genetic parameters of the univariate case. In practice, a close approximation to this correlation can be obtained from an $\mathrm{F}_{2}$ triple test-cross which also provides the best estimates of all the other parameters required.

We have tested the predictive power of the extended method by the joint properties of the $80 \mathrm{~F}_{11}$ families of the $V_{1} \times V_{5}$ cross raised in 1973 in respect of both flowering time (FT) and final height $(\mathrm{FH})$ using estimates of parameters obtained from a triple test-cross of the $F_{2}$ of this cross raised in 1965 (table 3). We have also illustrated the procedures by showing how we can predict the joint properties of the $F_{11}$ families in respect of 10 pairs of characters (table 3) and one combination of three characters taken simultaneously (table 5) using estimates of parameters obtained from a triple test-cross of the inbreds themselves. On the whole the agreement between these predictions and the observed properties of the inbred lines is as good as for the univariate procedures described earlier and it is certainly good enough for most practical purposes. Statistical tests of the accuracy of the predictions, however, must await larger sample sizes than the 80 inbreds which are currently available. With this in mind, a number of experiments are in progress each of which will yield many hundreds of inbreds by single seed descent and provide estimates of all the parameters required for making the predictions from an $\mathrm{F}_{2}$ triple test-cross.

\section{ReFERENGES}

EAVES, L. J., AND BRUMPTON, R. J. 1972. Factors of covariation in Nicotiana rustica. Heredity, 29, 15I-175.

JINKs, J. L., AND POONI, H. s. 1976. Predicting the properties of recombinant inbred lines derived by single seed descent. Heredity, 36, 253-266. 
KEARSEY, M. J., AND JINKS, J. L. 1968. A general method of detecting additive, dominance and epistatic variation for metrical traits. I. Theory. Heredity, 23, 403-409.

MATHER, K., AND JINKs, J. L. 1971. Biometrical Genetics, pp. 382. Chapman and Hall, London.

oWEN, D. B. 1956. Tables for computing bivariate normal probabilities. Annals Math. Stat., 27, 1075-1090.

PERKINS, J. M. 1972. The principal component analysis of genotype environmental interactions and physical measures of the environment. Heredity, 29, 51-70.

PERKINS, J. M., AND JINks, J. L. 1970. Detection and estimation of genotype-environmental, linkage and epistatic components of variation for a metrical trait. Heredity, 25, 157-177. POoNI, H. S., AND JiNks, J. L. 1976. The efficiency and optimal size of triple test-cross designs for detecting epistatic variation. Heredity, 36, 215-227.

POONI, H. s., JINKs, J. L., AND CORNISH, M. A. 1977. The causes and consequences of nonnormality in predicting the properties of recombinant inbred lines. Heredity, 38, 329-338. sTECK, G. P. 1958. A table for computing trivariate normal probabilities. Annals Math. Stat., $29,780-800$. 